\title{
Adverse Event Related to Patient Condition
}

National Cancer Institute

\section{Source}

National Cancer Institute. Adverse Event Related to Patient Condition. NCI Thesaurus.

Code $C 91872$.

An existing condition or disease is demonstrably responsible for the adverse event and use of the device has neither caused nor otherwise influenced this condition/diseaserelated adverse event. 